\title{
A NEW CRETACEOUS CONIFER FROM NORTHERN ALASKA ${ }^{1}$
}

\section{Chester A. Arnold and J. Stewart Lowther}

ONE OF THE results of the 1951 University of Michigan paleobotanical expedition to northern Alaska (Arnold, 1952) was the discovery of a new fossil member of the Taxodiaceae that is intermediate between Taxodium and Metasequoia. It represents a heretofore unknown genus for which the name Parataxodium is proposed. Its only species, $P$. wigginsii, is named in recognition of Dr. I. L. Wiggins, who, at the time of the expedition, was scientific director of the Arctic Research Laboratory at Point Barrow, and whose interest in the project contributed much to the success of the venture.

The expedition, carried out during July and August of 1951, was for the purpose of exploring Naval Petroleum Reserve No. 4 for fossil plants. It was financed by the Office of Naval Research with the Arctic Research Laboratory supplying equipment and serving as the operational base.

Because there are few named landmarks in that part of Alaska explored in 1951, the places where fossil plants were found are difficult to specify with precision. However, almost all maps of Alaska, even those of large scale, show a major bend in the Colville River about 75 miles south of the place where it flows into the Arctic Ocean. At this bend the river changes its course from an easterly one to almost due north. The new conifer was found about six miles downstream from this bend, on the right bank near the base of a high cliff. The locality is also three miles below the place where the Chandler River flows into the Colville and two miles upstream from the mouth of the Anaktuvuk River. Both of these tributaries, however, enter the Colville on the opposite side from where the plants were found. Positions of the lines of latitude and longitude differ as much as ten miles on different maps of the region under consideration, but on the Umiat map sheet of the Alaska Reconnaissance Topographic Series of the United States Geological Survey, Edition of 1952, the plant locality is in the vicinity of the place where parallel $69^{\circ} 30^{\prime}$ north crosses meridian $151^{\circ} 30^{\prime}$ west.

The high cliffs that flank the west bank of the Colville River extend for several miles both upstream and downstream from the plant locality. At places they rise precipitously from the edge of the water to heights of 100 feet or more. Above the initial rise they may continue upward less steeply to still greater heights. The cliffs form a prominent headland in the angle of the bend mentioned above. Downstream for a few miles they trend away from the river channel but approach it again in the vicinity of the place where the plants were found.

1 Received for publication February 1, 1955.
Along that part of the Colville River where the plant discovery was made, the exposed rocks belong to the Colville group which is considered to be of Upper Cretaceous age. This group consists of two intertonguing formations, the Prince Creek, which is non-marine. and the Schrader Bluff which is marine (Gryc et al., 1951; Payne, 1951). The plants were found in the Kogosukruk tongue of the Prince Creek formation which is made up principally of bentonitic clays, siltstones, and layers up to four feet thick of bony coal.

The rock that contains the plants is an irregularly bedded, light-gray, rusty-weathering, ferruginous limestone that contains about 73 per cent calcium carbonate. Its fine-grained texture, lack of coarse components, and the inclusion of large quantities of extremely fragile plant fragments indicates origin from sediments carried in slowly moving water. All the material of the new conifer came from one block of this limestone about two feet thick that had fallen from an outcrop in the cliff above the river. Although parties representing the United States Geological Survey had measured several sections in this cliff near the plant locality, no limestone is mentioned in connection with any of the sections.

The new conifer is represented by numerous fragmentary specimens of leafy shoots (fig. 1-3, 5, 8,11 ), several detached seed cones (fig. $4,9,10$ ), portions of staminate inflorescences (fig. 5, 6, 12), and badly preserved seeds, all believed to belong to the same species. After treatment for a few seconds with 5 per cent hydrochloric acid, the brownish-black compressions stand out in sharp contrast to the lighter-colored matrix. The tissues had become altered to the extent that scarcely a trace of structure remains. The dark rustlike residue adheres firmly to the limestone and splits with the rock when the latter is broken. For this reason surface features of the leaves and cones are not revealed well, a fact that is particularly disadvantageous in the cones because the arrangement of the cone scales cannot be observed.

The broken condition of the twigs and the fact that many of their leaves are missing indicates that the material had lain on the ground for considerable time before removal to the ultimate site of deposition. At some stage in the process the twigs had obviously become dry and brittle. A noticable feature is the lack of marginal curling that com. monly results when fresh leaves are removed from a tree and dried.

The environment under which the plants grew and the circumstances of their preservation are believed to have been approximately as follows. A climax forest in which Parataxodium wigginsii was the dominant species covered a broad expanse of 
low ground that probably formed the floor of a broad valley. The terrain became periodically inundated by the seasonal overflow of a sluggish strearn that followed a tortuous course through the area. With recession of the backwaters that annually spread over the nearly level terrain, the litter of deciduous shoots and cones that had been shed the previous autumn was carried away. The debris sank in a nearby shallow lake, possibly an oxbow lake, and was immediately covered with fine mud. This mud became saturated with calcium carbonate which during the following summer precipitated out of solution when the temperature of the water increased. Small amounts of typical bog iron ore were also formed, as shown by the rich iron oxide content of some of the rock layers. This sedimentation process was repeated year after year until the limey deposit with its high content of partially disintegrated plant contents reached a considerable thickness. Subsequent burial beneath additional sediments ultimately produced the fossiliferous fine-grained tresn-water limestone that is exposed in the bluff along the Colville River today.

The leaves and leafy shoots.-The disadvantages imposed by the fragmentary condition in the study of the leafy shoots are partly outweighed by the abundance of material. Although no complete twigs were found, it is evident that the trees did shed whole leafbearing shoots, and that the shedding was annual, as in Taxodium and Metasequoia. It is also evident that the trees produced both long and short shoots. Some of the specimens are branched like the long shoots of the modern genera (fig. 1,2 ), and some of the simple ones bear carbonized remains of the whorl of basal bracts which ornament the short shoots of the living trees.

The shoots had lost so many of their leaves that the arrangement can be observed on a relatively small proportion of them (fig. $2,5,7,8,11$ ). However it is obvious that the alternate arrangement predominates (fig. $5,7,11$ ), although a few of the leaves are opposite (fig. 2,8). The latter condition never involves a whole twig and seems to be confined to the tip portions. The small axillary lateral branchlets on what are believed to be the long shoots have more opposite leaves than the main axes (fig. 2) but there are only a few such specimens in the collection on which the arrangement is visible. It is also evident that those branchlets with opposite leaves are axillary to alternately borne leaves on the larger axes (fig. 2). The alternate and spiral arrangement is clearly the rule, a feature that Parataxodium shares with Taxodium and Sequoia.

The leaves of Parataxodium show about as much variation as one normally sees in conifer leaves. Those on twigs believed to be the main axes of long shoots are longest (fig. 11), sometimes as much as $20 \mathrm{~mm}$. long. Those on lateral shoots and the short shoots are smaller, commonly ranging between 5 and $10 \mathrm{~mm}$. in length. Some are no more than $3 \mathrm{~mm}$. long, but these very small leaves are mostly on the terminal parts of lateral branch. lets. The angle of departure corresponds somewhat with length. Those that exceed the median stand out at angles as wide as $80^{\circ}$ (fig. $1,3,5,7,11$ ), whereas the smaller ones show less spread. The larger leaves are linear-oblong with nearly parallel sides (fig. $5,7,11$ ), but the lanceolate form is approached in the smaller ones (fig. 8). The apex varies somewhat with the form, being distinctly obtuse in linear-oblong specimens and more acute in the others (fig. 2, 8). However, the tip is never drawn out to a sharp point, not even in the most lancelolate examples. This particular feature, the blunt apex, is useful for comparison of Parataxodium with other genera. Well-preserved leaves show a distinct though minute terminal mucro (fig. 7) that is not always visible without a lens. On the better preserved leaves a small but distinct midrib shows.

The leaves are attached to the twigs by a short but distinct stalk. Below the point of attachment the stalk continues down the side of the twig, but owing to the lack of surface preservation the downward course is not clear. However, where this part of the leaf base shows at all, the downward course seems to be parallel to the twig, as in Taxodium, rather than oblique, as in Sequoia and Metasequoia. The base of the leaf blade is acute or rounded, depending on whether the apex tapers or not.

Associated seed cones. - A number of detached seed cones are believed to belong to the leafy shoots among the fragmentary remains in the limestone matrix. They bear a general resemblance to cones of the Taxodiaceae and to Metasequoia in particular, but the scale pattern is obscured by failure of the rock to separate from the cone surfaces. They are smaller than most taxodiaceous cones, measuring only about $10 \mathrm{~mm}$. by $13 \mathrm{~mm}$. in length and breadth (fig. 9, 10). Each is borne on a naked pedicel that is about as long as the axis of the main part of the cone. The slightly irregular surface of the pedicel (fig. 4) indicates that it formerly bore appendages which are not preserved. The scales are persistent, terminally enlarged, and slightly separated (fig. 4).

A matter to be considered at this point is the nature of the evidence that the cones and leafy shoots were borne on the same trees. The mere fact of association alone is insufficient. There should be other criteria. In this instance the foliage shoots bear a strong resemblance to Taxodium and the seed cones show distinctive characteristics of Metasequoia. But to assign the shoots and cones to these genera separately, it would be necessary to assume that there existed on the ancient landscape of northern Alaska either a mixed stand of Taxodium and Metasequoia or a forest in which the two trees grew sufficiently close together that their remains could become preserved in the same deposit. From the purely ecological standpoint an associa- 

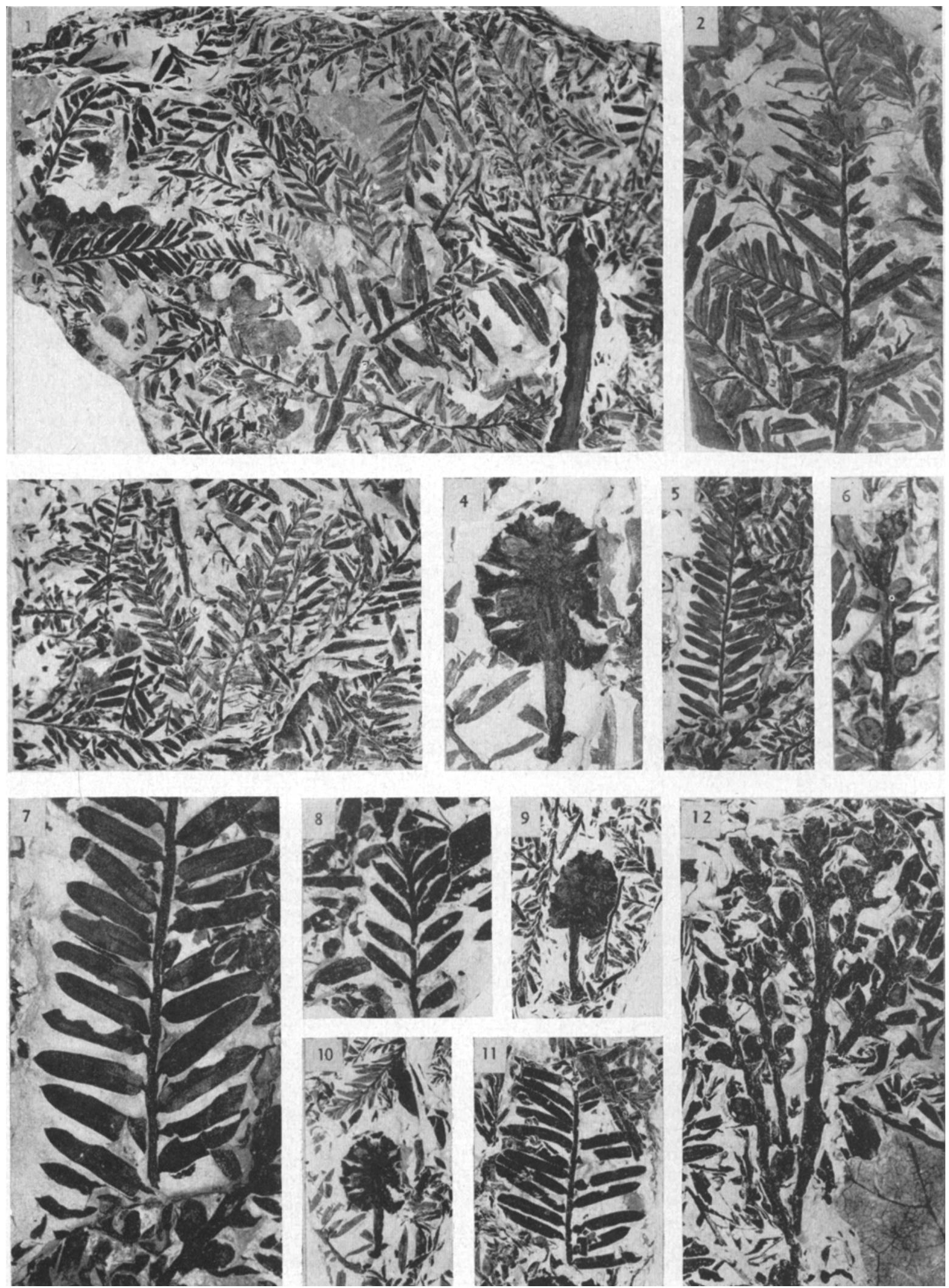
tion of this kind could have existed, but if it did the leafy twigs and cones of both should have found their way into the same shallow lake. Such, however, is definitely not the case. The leafy shoots are all of one kind. It is true that plants from widely separated places are often brought together in one fossiliferous deposit, and organs like solidly constructed cones can be carried much farther by running water without being destroyed than can more delicate leafy twigs. But parts brought great distances are usually lesser elements in fossil assemblages. There is no evidence that any of the plant remains in the limestone under consideration were other than local in origin, and all evidence points to the conclusion that the twigs and cones belong to the same species.

Associated staminate inflorescences.-Several portions of staminate inflorescences were found among the leafy shoots. The inflorescence has a rather stout central axis with slender branches that bear nearly opposite bracts in the axils of which there are small broadly oval staminate cones about 2 mm. long (fig. 12). Detached branches (fig. 5, 6) resemble the staminate spikes of Metasequoia except for the slightly wider spacing of the cones. The whole inflorescence, on the other hand, is much like that of Taxodium, T. mucronatum in particular, The bracts, which are about $5 \mathrm{~mm}$. apart, are about twice as long as the cones, and are persistent. The largest specimen found (fig. 12), is about $40 \mathrm{~mm}$. long and bears portions of five branches.

Comparisons with other genera of the Taxodiaceae.-The leaf arrangement in Parataxodium is so like that in Taxodium and Sequoia that the detached shoots could easily be mistaken for one of these genera if only casually examined. Of the two, the closer resemblance to Taxodium is obvious. The more delicate foliage, the slender shoot axis, the constricted leaf base, the conspicuous midrib, and the apparently deciduous habit are features so closely matched in Taxodium that Sequoia hardly deserves further consideration. Other than leaf arrangement, there is little to indicate close relationship with Sequoia.

Although the leaf arrangement of Parataxodium is like that of Taxodium, the individual leaves are more like those of Metasequoia. One obvious resemblance is the angle of divergence of the leaves from the stem. In his comparison of leaves of Metasequoia, Taxodium and Sequoia, Chaney
(1951) claims that the angle of divergence provides a means of separating the three genera in fossil specimens. The angle is widest in Metasequoia, commonly being about $90^{\circ}$. Sequoia leaves diverge at about $45^{\circ}$ on the average, but in Taxodium the angle of divergence is still lower. Chaney warns, however, that this particular feature can lead to error if only a few specimens are examined. As stated before, the leaves of average length and longer on the shoots from the Colville River may show a spread of as much as $80^{\circ}$, which is closer to Metasequoia than to Taxodium or Sequoia. An angle less than $45^{\circ}$ is displayed only near the branch tips where the condition is localized. The leaf spread, therefore, when compared with that of the three extant genera, is nearest Metasequoia and furthest from Taxodium.

A second point of resemblance to Metasequoia, and probably a more important one, is the shape of the leaf, particularly the apical part. In fact, if the leaves of Parataxodium were all found detached, they would be identified as Metasequoia leaves without hesitation. Chaney (1951, p. 178) characterizes Metasequoia as "narrowed slightly if at all distally, with a blunt mucronate apex." The leaves of Taxodium are more consistently acute. In making the present study this feature has been verified by both fresh and herbarium specimens. Chaney does not mention the terminal mucro in Taxodium which we find to occur quite consistently in Taxodium mucronatum and frequently in $T$. distichum. Because a mucro seems to be present in all genera concerned, it has no taxonomic value. The mucro, however, is something apart from the shape of the apex. As previously stated, the larger leaves of Parataxodium are linear-oblong (fig. 5, 7,11 ) with nearly parallel margins and blunt apices. Then the smaller leaves, though having a more lanceolate form, show, in the majority of instances, a blunt apex which is similar to that of the larger leaves. This feature stands out distinctly from the acute apex of the living as well as of authentically identified fossil specimens.

The cones associated with the leafy shoots of Parataxodium wigginsii bear an unquestioned resemblance to Metasequoia cones. The arrangement of the cone scales, whether decussate or spiral, unfortunately does not show well, but other features, particularly the naked stalks and the non-deciduous scales are distinctly features of Metasequoia.

Fossilized leafy shoots of conifers with cones

Fig. 1-12. Foliage, seed cones, and staminate inflorescences of Parataxodium wigginsii Arnold \& Lowther gen. et sp. nov. - Fig. 1. Fragments of long and short shoots strewn over surface of limestone block. Nat. size.-Fig. 2. Portion of long shoot bearing alternate leaves and axillary branchlets on which some of the leaves are opposite. Paratype. $\times 2$.Fig. 3. Fragments of short shoots on surface of limestone block. Nat. size.-Fig. 4. Enlarged view of seed cone shown in fig. 4. $\times 2 .-$ Fig. 5. Short shoot bearing alternate linear-oblong leaves. Diplotype. Nat. size.-Fig. 6. Enlarged view of branch of staminate inflorescence lying diagonally across bottom of fig. 5 . Paratype. $\times 2$. - Fig. 7. Enlarged view of diplotype (fig. 5) showing arrangement of leaves, blunt apex with minute terminal mucro, and short petiole. $\times 3 .-F i g$. 8. Small branchlet bearing a few opposite leaves. $\times 3 .-$ Fig. 9,10 . Seed cones showing naked peduncles. Paratypes. Nat. size.-Fig. 11. Portion of shoot bearing long leaves. Paratype. Nat. size.-Fig. 12. Staminate inflorescence with portions of five branches which bear opposite bracts and axillary staminate cones. Paratypes. $\times 2$. 
attached are not often found. Such combinations are especially scarce in genera like Metasequoia and Taxodium which normally shed their cones each year, and in the latter, where the scales fall from the cone axis as well, chances of finding even whole detached cones are slight. The situation in Sequoia is different because its cones remain on the trees along with the foliage shoots for more than one year, and several instances are on record of fossil cones attached to shoots. Although attachment is seldom seen among fossil remains of Metasequoia, the cones themselves are sufficiently distinctive for identification.

Reasons for proposing a new genus.-Practically all the features of the associated leafy shoots, seed cones, and staminate inflorescences that are assigned to Parataxodium can be matched in Taxodium and Metasequoia; only the grouping of the characters is peculiar to the new genus. It is distinctly an intermediate genus, one of the so-called "transition conifers," that is distinguished from others by a combination of characters. To assign these fossilized parts to any previously-named genus would necessitate revision of the chosen one to conform to the new material. If the leafy shoots alone were taken into account, to the exclusion of other parts, and placed in Taxodium, the principal change would involve the shape of the leaf and the degree of spread of the leaves on the twigs and the opposite phyllotaxy of the leaves on small axillary lateral branchlets. However, it would be impossible to reconcile the seed cones with those borne by any of the living species of Taxodium. If, on the other hand, it were decided to assign arbitrarily the remains to Metasequoia on criteria furnished by leaf shape and the fact that a small fraction of the leaves is oppositely arranged, Metasequoia would then be receiving a species in which at least 95 per cent of the leaves are alternate. In our opinion a new genus is necessary because no other one is appropriate for the material under consideration. However, if it were assigned to either Metasequoia or Taxodium most of the important differences between them would be bridged, and this would amount to merging of the two genera, with Taxodium being the one with recognized priority. Indeed, such radical and extreme handling of these two well-defined genera would not be acceptable to any botanist familiar with them. So the only alternative to naming a new genus is to divide the remains between Taxodium and Metasequoia. This could be done only by assuming that the leafy shoots and seed cones belong to different plants.

Associated plants.-Parts of a few other plants are mixed with the fragmented remains of Parataxodium wigginsii. One is a coniferous needle assignable only to the form genus Pityophyllum. There are several specimens of a small-leaved Ginkgo, and fragments of an unidentified fern. A primitive dicotyledon is represented by portions of broad, crenately-margined, palmately-veined leaves.
At a place less than one-half mile downstream from where the limestone block containing the remains of Parataxodium wigginsii was found, and at approximately the same stratigraphic level but in a darker colored matrix, leafy twigs and cones resembling those of Sequoiadendron reichenbachi were collected. This is a common species in Cretaceous rocks of arctic regions.

Discussion.-After the discovery of living trees of Metasequoia following the initial finding of the fossil remains in 1941, the necessity for a complete rewriting of the geological history of the Taxodiaceae, particularly that part pertaining to Taxodium and Sequoia, became acutely realized. Almost all the North American material that had been assigned to Taxodium and Sequoia has been re-examined by Chaney (1951) who found that remains of these two genera and of Metasequoia had been badly confused. Because Metasequoia had not become generally known to American botanists before about 1948, fossil specimens of it had been placed by some authors in Taxodium and by others in Sequoia. The most noteworthy and oft-repeated error had been the use of the name Sequoia langsdorfii for fossil remains of Metasequoia, a mistake that had special significance in instances where arctic material was concerned. This misidentification commenced during the 1860's when Oswald Heer mistook some American material of Metasequoia for $S$. langsdorfii which he had previously identified in Europe. The error was subsequently perpetuated by Lesquereux, Dawson, Knowlton, Hollick, and all others who had had occasion to deal with fossil material of Taxodium and Sequoia. Not only did they accept Heer's original identification, but they failed also to observe the decussate arrangement of the leaves and cone scales which is a most obvious feature once attention is called to it. Chaney. has concluded that although $S$. langsdorfii may be a recognizable species in Europe where it was first described, it has not been found in North America. Everything that has been identified as $S$. langsdorfii in North America is something else, although the name has long been a favorite catchall for almost any fossil conifer with distichous foliage.

Chaney has reduced to two the list of eight fossil species of Sequoia that had been supposed to exist in North America. Sequoia dakotensis, an Upper Cretaceous species of limited occurrence, is known only from cone casts. The other, $S$. affinis, occurs widely in the Tertiary. These species exist in addition to the so-called "Sequoia" reichenbachi which belongs to Sequoiadendron and is different.

Sequoia affinis is regarded as the Tertiary equivalent of the living redwood, $S$. sempervirens, and is virtually indistinguishable from it. First named by Lesquereux in 1876, much material rightfully belonging to it has been identified as $S$. couttsiae, $S$. haydenii, S. heerii, and S. langsdorfii. Some of these names also covered material now known to belong to Metasequoia. Sequoia affinis is prevalent through- 
out the Tertiary of the northwestern United States and adjacent Canada, but has not been found in northern Canada or Alaska where it is not believed to ever have existed.

There are likewise two fossil species of Metasequoia in North America. Metasequoia cuneata comes from the Upper Cretaceous, and $M$. occidentalis extends from the Paleocene to middle Miocene. Both species occur in Alaska, but range southward, the latter as far as California, Nevada and Wyoming. Chaney believes that most of the material from high latitudes that was described by Heer as $S$. langsdorfii in his "Flora Fossilis Arctica" is $M$. occidentalis.

At least six species of Taxodium have been named from the North American continent, but Chaney recognized only one, Taxodium dubium, which is hardly different from the living $T$. distichum. Its earliest appearance is in the Paleocene of Alaska and Canada. In later stages of the Tertiary it appears farther south. Considerable material that has been placed in various species of Sequoia belongs to Taxodium.

Due to the confusion that was caused by dividing Metasequoia remains between Taxodium and Sequo$i a$, characters whereby Taxodium might be recognized in the fossil state were not well understood until Chaney re-examined the specimens that had been misidentified. He has set forth criteria whereby material of Taxodium that is well preserved and available in quantity can be distinguished from the other genera.

The discovery of Metasequoia has not only thrown light on some of the perplexing taxonomic problems pertaining to fossil members of the Taxodiaceae, but has resulted in a much better understanding of the geologic history of Sequoia and Taxodium than we had before. All the known fossil occurrences of Sequoia indicate that the genus has always been an inhabitant of the middle latitudes and has never thrived in the far north, as have Taxodium and Metasequoia. This belief has support in the recent discovery of the oldest known Sequoia, S. jeholensis (Endo and Chaney, 1951) from the Middle or Upper Jurassic of Manchuria, at about $42^{\circ}$ north latitude. Sequoia jeholensis occurs well within the known latitudinal range of $S$. affinis during the Tertiary and $S$. sempervirens in Recent times.

Although the fossil record has not revealed either the exact time or place of the origin of any of the genera under consideration, we do know that Sequoia was in existence by the Middle or Late Jurassic, Parataxodium by the mid-Cretaceous, Metasequoia by the late Cretaceous, and Taxodium at the beginning of the Tertiary period. Sequoia, the first to be revealed by the fossil record, could have arisen in middle latitudes or it might have migrated into them from elsewhere. Whichever it was, one guess is about as good as the other, but in either event it is quite apparent that it diverged from its ancestral stock rather early in the Mesozoic era. Of the three genera-Sequoia, Taxodium, and Metasequoia - Sequoia evidently evolved first. The remaining genera came later, probably as a result of the early split in the ancestral stock. Thus one of the branches gave rise to Sequoia, and the other produced the secondary stock from which the other genera arose. Then the possibility that Paratax. odium might have been a member of the latter of the two stocks is indicated by its intermediate nature and by its occurrence in the far North where both Taxodium and Metasequoia make their initial appearance. The existence, though not necessarily contemporaneously, of these three genera in Alaska is good evidence for the boreal origin of all.

The possibility that Parataxodium might be in some way related to the ancestral stock of Taxodium and Metasequoia, or might indeed be the actual ancestral stock itself, finds further support in the position of Parataxodium in the geologic sequence. It is definitely older than any known Taxodium and is at least as old as Metasequoia. Although the rock in which Parataxodium is preserved is placed in the Upper Cretaceous, the general aspect of the florule of which it is a part is old, and is a type that would not be out of place in the Lower Cretaceous. Parataxodium may have existed during Lower Cretaceous times because some isolated cones that look much like Parataxodium cones were found in the Lower Cretaceous Nanushuk group along the Colville River in 1951 and again in rocks of similar age along the Kuk River in 1953. Although the evidence is not conclusive, it is possible that fragmentary foliage shoots from the Nanushuk group that can be referred only to the form genus Elatocladus are Lower Cretaceous examples of Parataxodium.

In summarizing the two preceding paragraphs, it should be said that the fossil record supports the tentative assumption that a major split took place in the ancient taxodiaceous stock at some time during the early part of the Mesozoic era. One of these branches gave rise to Sequoia of which $S$. jeholensis is the oldest known representative. The Sequoia stock became established in middle latitudes. The other line, of which Parataxodium is a member, took up its stand in the far North. Then from this, Metasequoia diverged first, then Taxodium. This order of appearance of the latter two genera is suggested by the earlier known appearance of Metasequoia in the fossil record. Although pollen identified as Taxodium is said to have been found in the Upper Cretaceous, no undoubted foliage remains have been observed in rocks below the Tertiary. Taxodium did not become widely distributed until the Tertiary.

Stebbens (1948) postulates that Sequoia sempervirens originated as an allopolyploid from hybrids between an early Tertiary or Mesozoic species of Metasequoia and some probably extinct type of taxodiaceous plant not unlike Sequoiadendron, Taiwania, and Athrotaxis. The assumption is, 
therefore, that Sequoia sempervirens is a relatively late product of evolution. Unfortunately, the chromosomes of Sequoia affinis (the assumed Tertiary equivalent of $S$. sempervirens) and the Jurassic $S$. jeholensis no longer exist, but if we assume that these two fossil species form a sequence in time with $S$. sempervirens, then the hybridization process that initiated the genus Sequoia must have taken place before the oldest known occurrence of the genus, which is Jurassic. At that time it is doubtful whether one of the ancestors could have been Metasequoia since we have no evidence that it is that old.

The subsequent history of the group under consideration involved the extinction of Parataxodium probably before the close of the Cretaceous period. For some reason it failed to reach the lower latitudes that Taxodium and Metasequoia did, and probably never became very widely distributed. It cannot be recognized with certainty among other Cretaceous floras from Alaska or in any of the other arctic floras that have been illustrated with sufficient adequancy to make identification reasonably certain. The other two genera succeeded in becoming established in places where long-range climatic fluctuations are less severe than in the far North, and in that way they have survived. That Taxodium, a genus that is now restricted to warm places, could have originated in the arctic seems strange, but such an origin is the one indicated by the fossil record.

\section{ORDER CONIFERALES}

\section{FAMILY TAXODIACEAE}

Parataxodium gen. nov. ${ }^{2}$ Woody plants bearing leaves on deciduous shoots of two kinds; short shoots with distichous alternately arranged leaves, and long shoots bearing small branchlets in the axils of alternately arranged leaves. Larger leaves linear-oblong, smaller ones lanceolate, with blunt apices and attached by short but distinct inconspicuously decurrent petioles. Seed cones oval, on naked peduncles, deciduous, with persistent scales. Staminate inflorescences branched, with small cones in axils of opposite or subopposite bracts.

Parataxodium wigginsii sp. nov. Leafy short

2 The prefix para denotes the systematic proximity of the new genus to Taxodium rather than implying similarity in age. shoots mostly under $50 \mathrm{~mm}$. long, and bearing linear-oblong to lanceolate alternately arranged leaves $5 \mathrm{~mm} .-10 \mathrm{~mm}$. long. Leaves on long shoots up to $20 \mathrm{~mm}$. long, alternate, and bearing in their axils small branchlets on which some of the small lanceolate leaves are oppositely arranged. Seed cones about $10 \mathrm{~mm}$. by $13 \mathrm{~mm}$. in breadth and length; peduncle about equal to length of cone. Staminate cones broadly oval, about $2 \mathrm{~mm}$. long, and axillary to bracts about $5 \mathrm{~mm}$. long.

Age.-Upper Cretaceous, Colville group.

Locality. $-69^{\circ} 30^{\prime}$ north latitude, $151^{\circ} 31^{\prime}$ west longitude, Naval Petroleum Reserve No. 4, Alaska.

\section{SUMMARY}

The name Parataxodium wigginsii gen. et sp. nov. is proposed for a new member of the Taxodiaceae from the Cretaceous of northern Alaska. The description is based on leafy twigs, seed cones, and staminate inflorescences preserved in limestone. The material resembles the debris on a forest floor that had been washed away by seasonal overflow. ings of a sluggish stream and carried into a shallow lake. The leafy twigs consist of deciduous long and short shoots that were borne and shed in the same manner as those on Taxodium and Metasequoia. Most of the leaves show an alternate arrangement although a few on the axillary branchlets of the long shoots are opposite. Although the arrangement would indicate close affinity with Taxodium or Sequoia, the angle of divergence of the leaves with the twigs and the shape of the individual leaves are strongly like Metasequoia. The small oval seed cones are also deciduous, and have persistent scales and naked peduncles at maturity like Metasequoia cones. The staminate inflorescences are branched much like those of Taxodium mucronatum but the small axillary pollen cones are mostly oppesite. Characters of Taxodium and Metasequoia are about equally balanced in Parataxodium, and this is the main reason for proposing a new genus. Parataxodium may represent the actual ancestral stock of Taxodium and Metasequoia, or it may be merely a close relative of this stock. It shows fewer resemblances with Sequoia which the fossil record indicates as having originated earlier.

\footnotetext{
Department of Botany and Museum of Paleontology, UnIVERSITY OF Michigan, Ann Arbor, Michigan
}

\section{LITERATURE CITED}

Arnold, C. A. 1952. Paleobotanical investigations in Naval Petroleum Reserve No. 4, Alaska. Science 116 (3003): 61-62.

Chaney, R. W. 1951. A revision of fossil Sequoia and Taxodium in western North America based on the recent discovery of Metasequoia. Trans. Amer. Phil. Soc. N.S. 40 (3) : 171-239.

Endo, S., and R. W. Chaney. 1951. A record of Sequoia in the Jurassic rocks of Manchuria. Bot. Gaz. $113(2)$ : 228-230.
Gryc, G., W. W. Patton, and T. G. Payne. 1951. Present Cretaceous stratigraphic nomenclature in northern Alaska. Jour. Wash. (D.C.) Acad. Sci. 41 (5) : 159-167.

Payne, T. G. (and others). 195I. Geology of the Arctic Slope of Alaska. U. S. Geol. Surv., Oil and Gas Investigations Map OM 126.

Stebeens, G. G. 1948. The chromosomes and relationships of Metasequoia and Sequoia. Science 108 (2796): 95-98. 